\title{
Correspondence
}

\section{Targeted MOOC captivates students}

In our experience, massive open online courses (MOOCs) can reach non-traditional and disadvantaged learners if they address a recognized need, support the educational requirements of the intended cohort and enable learning with tangible outcomes (see

E. J. Emanuel et al. Nature 503, 342; 2013).

The Wicking Dementia Research and Education Centre at Australia's University of Tasmania has developed a MOOC on understanding dementia. This attracted almost 10,000 people from more than 60 countries in July, of which $89 \%$ were women, $70 \%$ were over the age of 40 , and only $17 \%$ were educated beyond a bachelor's degree (compared with $44 \%$ reported by Emanuel and colleagues).

The course is tailored to the educational needs of the care workforce and family-based carers who support the more than 44 million people with dementia worldwide.

Our cohort-centric approach involved structuring the course to support non-traditional learners, including providing online technical and teaching support.
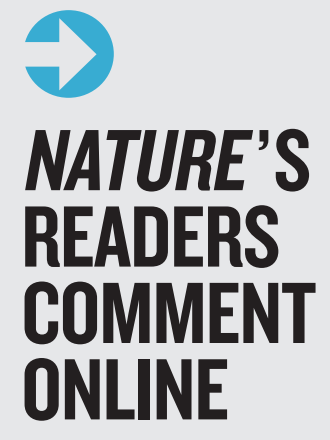

A sample of responses from the debate on the reproducibility drive (M. Bissell Nature 503, 333-334; 2013).
The completion rate for the 11 -week course was $39 \%$, which is considerably better than the international average for MOOCs (see C. Parr Times Higher Education 9 May 2013; go.nature.com/p25g67).

Carolyn King, Andrew Robinson, James Vickers Wicking Dementia Research and Education Centre, University of Tasmania, Hobart, Australia. carolyn.king@utas.edu.au

\section{Storm-surge impact depends on setting}

A storm surge on 5-6 December threatened urban centres and rural communities around the southern North Sea in a similar way to such an event 60 years ago. Causing more than 2,000 deaths, the 1953 flood was western Europe's most devastating in 100 years in terms of loss of life. Last month, however, a disaster was averted by advances in storm-surge forecasting, improved defences, early-warning systems and integrated crisis management.

Immediately after the surge, we made high-resolution measurements of maximum water levels, focusing on obvious debris lines, erosion points on earthen bank defences and water marks on buildings along the 45-kilometre-long northern coastline of Norfolk in the United Kingdom. These confirm that flood levels were similar to, and in places exceeded, those in the 1953 disaster.

There was considerable variation in the mean height of peak water levels along the shore (the maximum difference between measurement stations was more than 1.2 metres). This reflects the combined effects of tide, surge and wave run-up, which has a strong local component. For this coastline of barrier islands, spits and tidal embayments, these observations indicate that the coastal setting and extent of coastal ecosystems (such as mudflats and salt marshes) are critical in determining the pattern of storm-surge impacts.

Such differences become crucial when properties, infrastructure and lives are threatened by sea flooding (see also J. D. Woodruff et al. Nature 504, 44-52; 2013). These factors should be incorporated into hydrodynamic modelling and forecasting efforts, to help finetune early-warning systems and evacuation planning. Thomas Spencer University of Cambridge, UK. ts111@cam.ac.uk

Susan M. Brooks Birkbeck, University of London, UK. Iris Möller Cambridge Coastal Research Unit, UK.

\section{Whistle-blowers have a tough time}

Whistle-blower cases that go on forever are not uncommon (see Nature 503, 454-457; 2013). The cold conclusion is that the whistle-blower may survive, but the odds are against him or her.

I have worked with whistleblowers for more than 35 years as an expert witness in court cases and as author of the forthcoming book Don't Kill the Messenger (see www. whistleblowing.us), and find that they are hard to silence. The truth-telling part of their brain seems to override the health and safety part, so they will endure all forms of retaliation for the sake of truth.

Institutions can also be very slow to admit to any mistakes on their watch. This factor delays adjudication and makes it harder for the whistle-blower to prove anything in court.

Don Soeken Whistleblower Support Fund, Ellicott City, Maryland, USA.

helpline@tidalwave.net
Nitin Gandhi says:

The very fact that we have to take the issue of replication so seriously and spend lots of time and money on it in these hard times speaks out loudly that things are not right in biomedical research.

\section{William Gunn says:} The Reproducibility Initiative aims to make science work better for everyone [see go.nature.com/v5c1js]. The worst that could happen is that we learn a lot about what level of reproducibility to expect and how to reliably build on a published finding. At best, funders will start tacking a few per cent on to grants for replication purposes and publishers will start asking for it. That can only be good for science as a whole.

\section{Anonymous says:}

I would be a rich man if I had received a penny for every time I heard the expression "in our hands" at a scientific lecture. I disagree that "the push to replicate findings could shelve promising research and unfairly damage the reputations of careful, meticulous scientists". I believe that the opposite is true.
Scientists should be encouraged to report and publish when they fail to replicate each other's experiments. That will help science (but maybe not scientific careers) progress much faster.

Irakli Loladze says:

The current system does not penalize for publishing sexy but non-reproducible findings. In fact, such publications boost the chances of getting another grant. It is about time to end this vicious cycle that benefits a few but hurts science at large. 